\title{
Effect of tropical climate condition to compressive strength and microstructure properties of high performance fiber reinforced reinforced concrete (HPFRC)
}

\begin{abstract}
Additional of fiber in concrete creates fiber reinforced concrete (FRC) with an improvement of the mechanical properties of the concrete. However, fiber incorporation in FRC is limited to $2 \%$ to allow normal mixing procedure. To address this issue, high performance fiber reinforced concrete (HPFRC) is introduced and it is relatively new in construction industry. Since very limited information on its capacity in tropical climate condition exposure, this research focuses on investigation of compressive strength and microstructure properties of the produced concrete in tropical climate condition. In order to complete this research, grade 80 cement slurry is used with 3\%, 4\% and 5\% hooked-end steel fiber. Total numbers of 56 samples which are divided into 4 sets and exposed to two different curing methods namely water curing method and steam curing method at $80^{\circ} \mathrm{C}$. Out of the 4 sets, 2 sets are exposed to tropical climate condition using climatic chamber at $80 \%$ relative humidity (RH) and constant temperature of $35^{\circ} \mathrm{C}$ for 30 days. Compression and ultrasonic pulse velocity (UPV) tests are carried out at 28 days to identify its strength as well as integrity of the concrete produced. Scanning electron microscopy (SEM) analysis is done to ascertain the microstructure properties of HPFRC. The highest compressive strength of 152.2 MPa was recorded for steam curing samples after exposed to tropical climate condition for 30 days with $5 \%$ steel fiber volume.
\end{abstract}

Keyword: Concrete durability; Fiber reinforced concrete; High performance concrete 